Research Article

\title{
Effects of Process Parameters on Geometrical Characteristics and Microstructure of TiC Particle-Reinforced Co50 Alloy by Laser Cladding
}

\author{
Nga Pham Thi-Hong (D) \\ Mechanical Engineering Faculty, HCMC University of Technology and Education, 1 Vo Van Ngan St., Thu Duc District, \\ Ho Chi Minh City 71307, Vietnam \\ Correspondence should be addressed to Nga Pham Thi-Hong; hongnga@hcmute.edu.vn
}

Received 4 September 2020; Revised 18 January 2021; Accepted 2 February 2021; Published 5 March 2021

Academic Editor: Antonio Gloria

Copyright (C) 2021 Nga Pham Thi-Hong. This is an open access article distributed under the Creative Commons Attribution License, which permits unrestricted use, distribution, and reproduction in any medium, provided the original work is properly cited.

Laser cladding of Co50 alloy coating and Co50 composite coatings doped with 10, 20, and $30 \mathrm{wt} . \%$ TiC particles was performed on the $\mathrm{H} 13$ steel surface. The effects of $\mathrm{TiC}$ concentration on the phase composition, microstructure, and microhardness of the coatings were studied. The results indicated that, in $10 \% \mathrm{TiC}$ coating, the "bright band" is a quite flat-growth tissue, while with $20 \%$ TiC, the "white bright band" contains a large amount of black TiC particles. The composite coating Co50, $10 \% \mathrm{TiC}$, and $20 \% \mathrm{TiC}$ samples can clearly distinguish the cladding zone, bonding zone, and heat-affected zone, and a good metallurgical bond is formed between the coating and the substrate. The $30 \%$ TiC coating and the substrate are not well bonded, which is attributed to the high $\mathrm{TiC}$ content in the coating; however, it has the best surface morphology, and there is no porosity on the surface. $10 \% \mathrm{TiC}$ coatings have poor surface quality, show a spraying material phenomenon on two side edges which is quite serious, and a lot of porosity on the surface of the coating. In addition, $10 \% \mathrm{TiC}$ coating includes the original $\mathrm{TiC}$ particles and primary $\mathrm{TiC}$ particles that are precipitated in situ from the liquid phase during solidification; $20 \% \mathrm{TiC}$ coating indicates a large amount of $\mathrm{TiC}$ in the form of cross petals and twigs, and the figure points out that $\mathrm{TiC}$ exists like a large number of diffusely distributed spherical structures in the $30 \% \mathrm{TiC}$ coating. The coatings of $\mathrm{TiC} / \mathrm{Co}$ composite with less than $20 \% \mathrm{TiC}$ showed good metallurgical bonding characteristics with the H13 steel surface.

\section{Introduction}

H13 hot work molds are constantly subjected to physical and chemical wear and tear, thermal fatigue, erosion, stress corrosion, surface thermal welding, and other physical and chemical effects, as well as the effects of cold and hot alternating and impact loads during mechanical production and use. In this harsh environment, the mold is prone to failure in the form of thermal fatigue, thermal wear, and cracking, which leads to a significant reduction in the life of the mold. As one of the important parts of automobile engines, connecting rods have high requirements on their weight and appearance quality. The shape and size of the connecting rod are guaranteed by forging. The workpiece in the final forging process of the connecting rod is a preform after preforging of the bar material, the big end is the round bar material, and the small end has been flattened (as shown in Figure 1). The large-end projection of the forging die first comes into contact with the workpiece, and the plastic deformation of the workpiece begins to enter the forging model groove; when the two ends of the workpiece are plastically deformed, they contact the bridge, then the flow is blocked, and the workpiece gradually fills the groove. Therefore, this requires that the connecting rod forging die must have a very high precision, which also puts forward higher requirements on the die material.

Machining after forging has been a traditional manufacturing method widely used in hot forging dies $[1,2]$. How to improve the life of hot forging dies has always been one of the main tasks of forging die researchers. The 


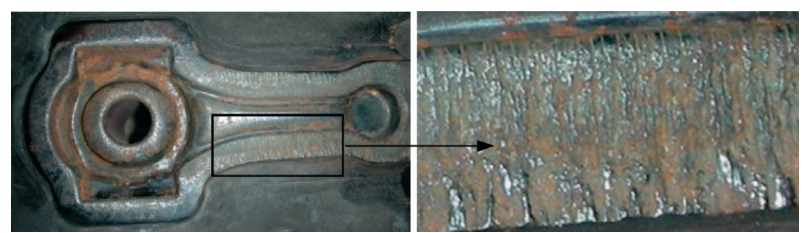

FIgURE 1: Hot die forging of the connecting rod and detail of the surface of the used $\mathrm{H} 13$ forging die showing severe plastic deformation.

traditional method of welding repair is used to repair the mold at the root of the groove, so that the mold can continue to be used without being scrapped. In response to this problem, existing studies have shown that laser repair of the H13 steel surface is a very effective method, and many researchers have also achieved some results in their laser surface modification $[3,4]$. Due to the rapid development of processing technology in the world, $1-20 \mathrm{~kW}$ lasers have been mass produced and used in many engineering fields; $100 \mathrm{~kW}$ high-power lasers and 3D five-axis $\mathrm{CO}_{2}$ lasers have been successfully developed and started to be popularized. Now, it has begun to develop high-power $\mathrm{CO}_{2}$ lasers, and the most widely used lasers are $1-5 \mathrm{~kW}$.

In recent years, China and other countries in the world have conducted more research on laser cladding (LC) technology, and it has reached the stage of industrial application. From LC powder materials, one of influencing factors of LC layer, many research studies have been conducted. According to previous studies, the hardness, wear resistance, and corrosion resistance of $\mathrm{H} 13$ steel can be improved to a certain extent after LC. Cao et al. [5] used a $5 \mathrm{~kW}$ cross-flow $\mathrm{CO}_{2}$ laser to prepare a Ni60A coating on the surface of $\mathrm{H} 13$ steel. The analysis showed that the coating and the substrate formed a good metallurgical bond, and the coating microhardness, which was $800-900 \mathrm{HV}$, was significantly higher than that of $\mathrm{H} 13$ steel. He used a $5 \mathrm{~kW}$ cross-flow $\mathrm{CO}_{2}$ laser to prepare Ni-based and Co-based coatings on the surface of $\mathrm{H} 13$ steel through multipass lap large-area cladding. Research shows that a good metallurgical bond is achieved between the coating and the substrate, and the microhardness of the multilayer lap coating is $\mathrm{Ni60A} \longrightarrow \mathrm{Co} 50 \longrightarrow \mathrm{Co} 42 \longrightarrow \mathrm{H} 13$ from high to low. Through a long-term high-temperature oxidation test, the hardness of Co-based alloy at high-temperature oxidation is studied. There is no decline; that is, Co-based alloy is better than Ni-based alloys [6]. In addition, in order to further improve the performance of the coating, researchers added various particle reinforcement phases to the cladding powder. Zhang et al. [7] conducted laser cladding WC particle-reinforced Ni-based powder experiments on the surface of $\mathrm{H} 13$ steel. The experiment showed that the coating has a dense structure, no cracks, pores, and other defects; the grain is refined, and it is firmly bonded to the substrate. A similar result was reported by Shao-yi et al. [8]; they used a $7 \mathrm{~kW}$ cross-flow $\mathrm{CO}_{2}$ laser to prepare a WC-Ni/TiC coating on the surface of H13 steel by LC. The results show that nano-TiC improves the hardness and toughness of the coating through dispersion strengthening and fine-grain strengthening.
Although LC technology has been widely used in parts repair and other fields, there are still many problems in the technology. Cracks and pore defects in the cladding layer are the main problems to be solved by material workers. The cracks of the LC layer are mainly related to four aspects: laser process parameters, process conditions, coating materials, and substrate conditions. In other words, the way to control the generation of cracks in the LC layer can be achieved by optimizing the laser process parameters, optimizing the process conditions, rationally designing the composition of the cladding layer, and improving the substrate condition. These measures are beneficial to reduce the source of cracks and pores and reduce the occurrence of cracks and pores. For the cracking of the coating, the researchers proposed the following solutions or mitigations:

(1) From the technical means, we optimize the process parameters and perform preheating and postheating treatment. In the actual preparation process, in order to further enhance the overall performance of the metal-ceramic composite coating, most of the current research focuses on various treatment methods after LC. Liu [9] used Co-based/WC mixed powder for powder feeding LC. The results showed that the cladding layer reheating treatment at $850{ }^{\circ} \mathrm{C}$ can achieve the purpose of stress relief annealing; the cladding layer is suitable for working under the environment of repeated heating and cooling in this temperature range. Studies of Chen et al. [10] have shown that, after laser remelting of the $\mathrm{WC} / \mathrm{Co}$ plasma sprayed layer on the surface of 45 steel, an LC layer with a metallurgical interface is obtained, which eliminates the pores and cracks in the plasmasprayed layer, and its structure and performance are obviously improved. Li et al. [11] also sprayed a layer of WC-12Co coating on a 45 steel surface and then performed laser remelting treatment. It was found that its wear resistance was nearly 3 times higher than that of the matrix structure.

From the existing literature, it can be seen that double-layer coating and multilayer coating cannot eliminate the problem of performance mismatch between the substrate and the coating and between the internal layers of the coating. In this regard, researchers began to explore the use of gradient coating, laminated cladding, or the introduction of a transition layer between the coating and the substrate. The purpose of the laminated cladding method is that, along the thickness direction of the coating, the content of the ceramic phase component gradually increases, and the content of the metal phase component decreases accordingly. The distribution law of ceramic particles in the coating shows a step change, the metal phase and the ceramic phase. There is no obvious interface between the coatings, so that the stress in the coating is weakened or eliminated to the greatest extent, and the bonding strength between the coating and the substrate is improved. The work of $\mathrm{Xu}$ et al. [12] adopted the 
layered cladding method to change the content and particle size of ceramic particles in the mixed powder layer by layer. After multiple layers of cladding, the distribution of ceramic particles in the coating showed a step change. However, there is no substantial difference between the layered gradient coating and the method of introducing a transition layer between the coating and the substrate, but the number of transition layers is increased. Some authors $[13,14]$ prepared a gradient-structure $\mathrm{TiC} / \mathrm{Ni}$ based composite coating by a one-step laser coating method and proposed to use the flow and solidification behavior of the laser melt pool, relying on the continuous growth and regular movement of TiC particles in the melt pool, which can automatically achieve the coating continuous gradient structure.

(2) From the aspect of alloying element toughening, toughness phases such as Ni and Co are added. From the aspect of grain refinement, rare earth oxides, some nanopowders, or a small amount of other metal elements are added to the cladding layer. Bisides, ultrasonic vibration or electromagnetic vibration is also applied [15]. Qiang, Fu [16] added an appropriate amount of $\operatorname{In}_{2} \mathrm{O}_{3}$ to the WC/Ni-based alloy powder to obtain a high-quality cladding layer without pores on A3 steel. Studies have shown that the addition of $\operatorname{In}_{2} \mathrm{O}_{3}$ inhibits the decomposition of WC, thereby reducing the content of $\mathrm{C}$ in the molten pool, reducing the possibility of forming $\mathrm{CO}$ and $\mathrm{CO}_{2}$ in the molten pool. Chen et al. [17] added a certain amount of metal reducing agent $\mathrm{Ti}$ during the cladding of $\mathrm{WC} / \mathrm{Co}$ cemented carbide with laser powder feeding, which effectively suppressed the porosity. However, Ti powder and $\mathrm{In}_{2} \mathrm{O}_{3}$ are expensive, and their use will increase the cladding cost to some extent. On the other hand, $\mathrm{Al}$ and $\mathrm{C}$ can better combine with oxygen to form $\mathrm{Al}_{2} \mathrm{O}_{3}$ with high chemical stability, which reduces the oxygen content in the molten pool, thereby effectively inhibiting the generation of stomata. Because the density of $\mathrm{Al}_{2} \mathrm{O}_{3}$ is very small, $\mathrm{Al}_{2} \mathrm{O}_{3}$ will float on the surface of the cladding layer to form slag during the cladding process, which further protects the cladding layer [18]. A similar result was reported by Xiao-Wei $[19,20]$; the results showed that the addition of $\mathrm{Al}_{2} \mathrm{O}_{3}$ has the effect of changing the microstructure and performance of the LC layer. The microstructure is refined, and wear resistant has been significantly improved. Several authors prepared nano- $\mathrm{Al}_{2} \mathrm{O}_{3} /$ Co-based coatings on the surface of Ni-based superalloys. The results showed that the addition of nano- $\mathrm{Al}_{2} \mathrm{O}_{3}$ changed the growth morphology of the interface from elongated columnar dendrites to shorter dendrites; when the content of nano- $\mathrm{Al}_{2} \mathrm{O}_{3}$ is more than $1 \%$, an equiaxed dendrite structure is obtained on the entire section; nano- $\mathrm{Al}_{2} \mathrm{O}_{3}$ serves as the core of heterogeneous nucleation, which refines the structure; nano- $\mathrm{Al}_{2} \mathrm{O}_{3}$ is unevenly distributed in the cladding layer, which promotes the transformation of $\gamma$-Co to $\varepsilon$-Co $[21,22]$.

In general, using optimized process parameters, preheating, postheat treatment, adding tough phase, adding rare earth oxides, adding a small amount of other metal elements, or performing ultrasonic vibration or electromagnetic vibration on the cladding layer have achieved good results, but did not fundamentally solve this problem. The reason is mainly because LC uses thermal spray alloy powder for a long time, but there is no series of alloy powder specially used for the LC process. In addition, because there is a significant difference between the thermal expansion coefficient and the elastic modulus between the metal-based alloy and the strengthened ceramic phase, this will cause a temperature gradient in each phase in the molten pool, thereby causing thermal stress and the formation of holes and cracks. In the abovementioned research, alloying elements such as $\mathrm{B}$ and $\mathrm{Si}$, which are relatively high in selffusible alloy powder, are prone to form low-melting liquid films such as borosilicate in the laser melt pool, and the liquid film breaks during the rapid solidification of the laser melt pool. It is easy to become a source of cracks later [23]. From this perspective, trying to reduce the content of $B$ and $\mathrm{Si}$ elements in the traditional self-fusible alloy powder should reduce the tendency of crack formation. Wang et al. used self-designed alloy powder to reduce the content of B and Si elements. The results show that by controlling the content of B and Si elements, crystal cracks can be prevented and performance requirements can be met [24]. However, the content of B and Si elements should not be too small because the reduction of these two elements in the powder will inevitably cause a decrease in the surface finish of the cladding layer $[25,26]$.

From the results of the abovementioned research, during the LC process, on the one hand, the difference in the temperature gradient and thermal expansion coefficient between the cladding layer and the base material often causes the mold surface to be uneven, and the composition of the cladding layer is not uniformly controlled. On the other hand, due to moisture and oxidation during cladding of the coating powder before cladding, pores are easily generated in the cladding layer; in addition, due to the extremely fast laser heating and cooling speed, the mold surface is prone to burn damage, deformation, cracks, and other phenomena. In order to solve this problem, several authors used LC technology to prepare H13-TiC composite coatings with different $\mathrm{TiC}$ content on the surface of $\mathrm{H} 13$ steel. The analysis believed that the combined effect of dispersion and fine-grain strengthening in the cladding layer and the hardness and strength of the coating after LC are significantly higher than those of the substrate, but with the increase in TiC content, the presence of too much second phase increases the chance of crack nucleation and propagation, resulting in a decrease in the tensile strength and fracture toughness of the composite material [27]. Xiaodan et al. [28] showed that the scanning speed has a greater 
influence on the morphology and size of the particles; the $\mathrm{TiC}$ content has a great influence on the morphology and particle size of the fine precipitated $\mathrm{TiC}$; and with the increase of $\mathrm{TiC}$, the corrosion resistance decreases.

Beside the LC parameters, the cladding material plays a critical role in the formation of a high-quality coating. The cladding material system varies from single alloy to multiple ceramics or alloys. In this, the melting alloy layers of the metal platform technology have developed rapidly, intending to enhance the corrosion resistance of a material such as Co-based alloys, Ti-based alloys, Fe-based alloys, and Ti-based alloys. From the perspective of the repair layer material, Co-based alloy coating can obtain high oxidation resistance, high temperature strength, high temperature hardness, and thermal fatigue resistance, which is very suitable for hot work of die steel. In a recent paper, Zhang et al. [29] performed LC on the surface of $2 \mathrm{Cr} 13$ stainless steel. The test results show that, by selecting appropriate laser irradiation process parameters, a Co-based alloy coating with an excellent performance can be obtained. In addition, Li et al. [30] used laser-clad Hoganas Cobased alloy on a Ni-based cast superalloy/45\# steel substrate with a broadband and narrow-band laser to prepare a defectfree coating; the result showed that a new type of fine dendrites with a crystalline direction parallel to the laser scanning speed was found. From the current research status, the addition of $\mathrm{WC}, \mathrm{B}_{4} \mathrm{C}, \mathrm{SiC}, \mathrm{C}_{\mathrm{r} 2} \mathrm{C}_{3}$, TiN, and other ceramic particles to the Co-based alloy can significantly improve the performance of the coating. Songhua et al. [31] prepared Co55 alloy coating, Co-based $/ 20 \% \mathrm{SiC}_{\mathrm{p}}(\mathrm{CoSiC})$ coating, and Co-based $/ 20 \% \mathrm{~B}_{4} \mathrm{C}_{\mathrm{p}}$ $\left(\mathrm{CoB}_{4} \mathrm{C}\right)$ on a $16 \mathrm{Mn}$ steel surface. It is found that $\mathrm{CoSiC}$ coating and $\mathrm{CoB}_{4} \mathrm{C}$ coating have higher hardness and better wear resistance than Co55 coating, in which CoSiC coating has the highest hardness and wear resistance. Among carbide ceramic particles, TiC has high hardness, good thermal stability, high melting point, and good resistance to high-temperature oxidation. Studies of Emamian et al. [32, 33] showed that compared with WC, TiC has a lighter weight and higher hardness and has a better effect than WC as a reinforcement and can obtain higher wear resistance. Although the ceramic phase can improve the hardness, its thermal and physical properties differ greatly with the metal matrix. For example, the melting point of the ceramic phase is much higher than that of the metal matrix, and the thermal expansion coefficient, elastic modulus, and thermal conductivity are very different. The temperature gradient of the molten pool area formed after laser irradiation is very large, resulting in large thermal stress, so the coating often has holes and microcracks [34-37]. This requires materials workers to further study the behavior of carbides in the LC layer, as well as the basic theory and production process of laser surface strengthening, which lays a foundation for the successful application of LC carbide/metal-based composite coatings in actual production.

\section{Materials and Methods}

H13 steel was selected for the experiment, and its chemical composition is shown in Table 1; a steel sample of $30 \mathrm{~mm} \times 10 \mathrm{~mm} \times 100 \mathrm{~mm}$ was used. Before testing, the samples are cleaned, rinsed with alcohol and acetone, and then, dried by using an oven. Self-melting Co50 alloy powders have the chemical components listed in Table 1 , with particle size $\sim 53 \mu \mathrm{m}$; TiC powders have $1 \sim 10 \mu \mathrm{m}$ particle size (Figure 2).

The process is coating the test sample by a preplaced powder layer using a homemade binder and then applying LC to melt it. Preplaced powder layers include a Co50 alloy powder layer and a Co50+10\%, Co50+20\%, and $\mathrm{Co} 50+30 \% \mathrm{TiC}$ composite powder layer (\% by weight), with $\sim 1 \mathrm{~mm}$ thickness. $\mathrm{n}$ electronic balance is used to weigh the cladding powder according to the abovementioned composition ratio. Before the experiment, those preplaced powder layers were added with a $3 \mathrm{wt} . \%$ homemade binder polyvinyl alcohol organic adhesive on the surface of H13 steel. After preplacing, the thickness is about $1 \mathrm{~mm}$. The preplacing coating sample was dried by using the oven for 8 hours before being melted away by LC.

Laser cladding of Co50 and Co50/TiC coatings is made on the type of GS-6000 TFL transverse-flow $\mathrm{CO}_{2}$ with the remaining technology parameters given in Table 2, the distance from the laser head to $\mathrm{H} 13$ steel surface is $55 \mathrm{~mm}$, and flow of Ar protecting the coating is $8 \mathrm{~L} / \mathrm{min}$.

After the LC experiment, first, the surface formation is observed to see whether the surface of the cladding layer is smooth, whether there are ripples and unevenness, and whether there are pores, slag inclusions, and preliminary observation of the surface cracks with a magnifying glass. The experiment used aqua regia $\left(\mathrm{HCl}+3 \mathrm{HNO}_{3}\right)$ to corrode the metallographic sample of Co-based coating for $15 \mathrm{~s}$, and the TiC/Co-based coating was saturated with $\mathrm{FeCl}_{3}$ and $\mathrm{HCl}$ saturated solution The microstructure was observed after 2 minutes of corrosion.

The microstructure morphology of the coating was observed using a LEICA DFC280 optical image analysis system and Philips XL30ESEM-TMP scanning electron microscope with a resolution of $3.5 \mathrm{~nm}$. The EDAX-Phoenix integrated energy spectrometer included in the scanning electron microscope was used to analyze the EDS spectrum of the coating section.

The experimental samples were processed by wire cutting into blocks with a size of $20 \mathrm{~mm} \times 6 \mathrm{~mm} \times 4 \mathrm{~mm}$, and then, the coating surface was mechanically polished by $400 \#$, $600 \#$, and $800 \#$ metallographic sandpaper in turn, the polished test. The sample was washed in absolute ethanol, then dried with a blower to make a metallographic sample, and placed in a dry box for use.

\section{Results and Discussion}

3.1. Analysis of the Overlay Shape. The technology parameters have a decisive influence on the shape of the coating and the microstructure of the coating. The main technological parameters include laser power $(P)$, laser spot size (diameter $D$ or area $S$ ), laser beam scanning speed $\left(v_{s}\right)$, the method of adding materials to the coating, and methods of protecting molten lakes. Normally, the selection of the technological parameters is mainly based on the experimental data planning method. 
TABle 1: Chemical composition of H13 steel and Co50 alloy powder used in experiments (\% by weight).

\begin{tabular}{lccccccccccc}
\hline Element & $\mathrm{C}$ & $\mathrm{Si}$ & $\mathrm{Cr}$ & $\mathrm{Mo}$ & $\mathrm{V}$ & $\mathrm{Mn}$ & $\mathrm{Fe}$ & $\mathrm{W}$ & $\mathrm{B}$ & $\mathrm{Ni}$ & $\mathrm{Co}$ \\
\hline H13 steel & 0.43 & 1.17 & 4.79 & 1.38 & 0.94 & 0.48 & $\mathrm{Bal}$. & - & - & - & - \\
Co50 alloy & 0.6 & 3.5 & 20.0 & 5.1 & - & - & 5.0 & 3.0 & 2.25 & 14.0 & Bal. \\
\hline
\end{tabular}

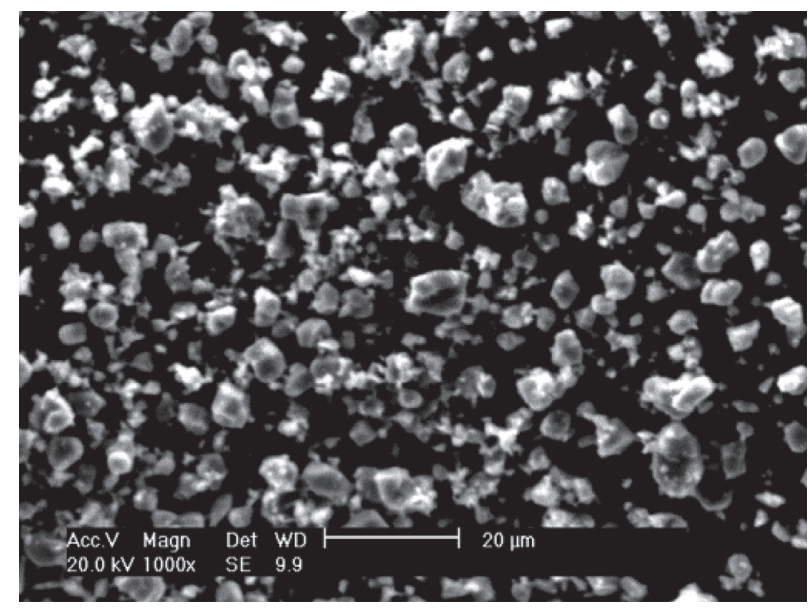

Figure 2: Topography of TiC powder used for laser cladding.

TABLE 2: The experimental parameters applied in the laser cladding.

\begin{tabular}{lcccc}
\hline Sample & $\begin{array}{c}\text { Component ratio (TiC: Co50) } \\
(\% \text { by weight })\end{array}$ & $\begin{array}{c}\text { Laser power } P \\
(\mathrm{~kW})\end{array}$ & $\begin{array}{c}\text { Scanning speed, } V_{\mathrm{s}} \\
(\mathrm{mm} / \mathrm{min})\end{array}$ & $\begin{array}{c}\text { Laser energy density, } P_{\mathrm{w}} \\
\left(\mathrm{kW} . \mathrm{s} . / \mathrm{cm}^{2}\right)\end{array}$ \\
\hline A1 & $1: 0$ & 3.3 & 350 & 14.37 \\
$\mathrm{~A} 2$ & $1: 0$ & 3.3 & 400 & 12.57 \\
A3 & $1: 0$ & 3.3 & 450 & 11.18 \\
A4 & $1: 0$ & 3.3 & 500 & 10.06 \\
B1 & $9: 1$ & 3.6 & 350 & 15.68 \\
B2 & $9: 1$ & 3.6 & 400 & 13.72 \\
B3 & $9: 1$ & 3.6 & 450 & 12.19 \\
B4 & $9: 1$ & 3.6 & 500 & 10.97 \\
C1 & $4: 1$ & 3.9 & 350 & 16.98 \\
C2 & $4: 1$ & 3.9 & 400 & 14.86 \\
C3 & $4: 1$ & 3.9 & 450 & 13.21 \\
C4 & $4: 1$ & 3.9 & 500 & 11.89 \\
D1 & $7: 3$ & 4.2 & 350 & 18.29 \\
D2 & $7: 3$ & 4.2 & 400 & 16.00 \\
D3 & $7: 3$ & 450 & 14.22 \\
D4 & $7: 3$ & 4.2 & 500 & 12.80 \\
\hline
\end{tabular}

Table 3 illustrates the surface morphology and macrograph of the A group sample. Co50 coatings have the characteristic bright white color. Looking at the detail, group A coatings have a relatively smooth surface, the surface is relatively smooth, and the two side edges are also quite smooth.

Table 4 presents the surface morphology and macrograph of the B group sample. Overall, it can be seen that when adding TiC in the coating, its appearance changes from bright white to black color. Unlike Co50 coatings with bright white color, group B coatings have a poor surface quality, show a spraying material phenomenon on 2 side edges which is quite serious, and a lot of porosity on the surface of the coating.

Table 5 shows the surface morphology and macrograph of the $\mathrm{C}$ group sample. It can be seen that group $\mathrm{C}$ has better quality than group B, with no cracks; however, the height of the coating is not uniform. Besides, there are a few particles of the material being shot during the LC process and the surface of the coatings still has porosities, especially $\mathrm{C} 3$ and $\mathrm{C} 4$ are peeled in some part of the coatings.

Lastly, group $D$ has the best surface morphology ( $\mathrm{Ta}-$ ble 6). When adding $\mathrm{TiC}$, with the increasing of $\mathrm{TiC}$ ratio, the quality of the coating surface also increases. There is no air 
TABLE 3: The surface morphology and macrograph of the A group.

\begin{tabular}{|c|c|c|}
\hline Coating & Surface morphology & Macrograph \\
\hline A1 & 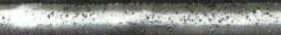 & \\
\hline $\mathrm{A} 2$ & 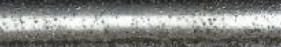 & \\
\hline A3 & Q & \\
\hline A 4 & 80 of & \\
\hline
\end{tabular}

TABLE 4: The surface morphology and macrograph of the B group.

\begin{tabular}{|c|c|c|}
\hline Coating & Surface morphology & Macrograph \\
\hline B1 & & \\
\hline B2 & & \\
\hline B3 & & \\
\hline B4 & & \\
\hline
\end{tabular}


TABLE 5: The surface morphology and macrograph of the $\mathrm{C}$ group.

\begin{tabular}{|c|c|c|}
\hline Coating & Surface morphology & Macrograph \\
\hline \multicolumn{3}{|l|}{$\mathrm{C} 1$} \\
\hline \multicolumn{3}{|l|}{$\mathrm{C} 2$} \\
\hline \multicolumn{3}{|l|}{$\mathrm{C} 3$} \\
\hline $\mathrm{C} 4$ & $g x$ & \\
\hline
\end{tabular}

TABle 6: The surface morphology and macrograph of the $D$ group.

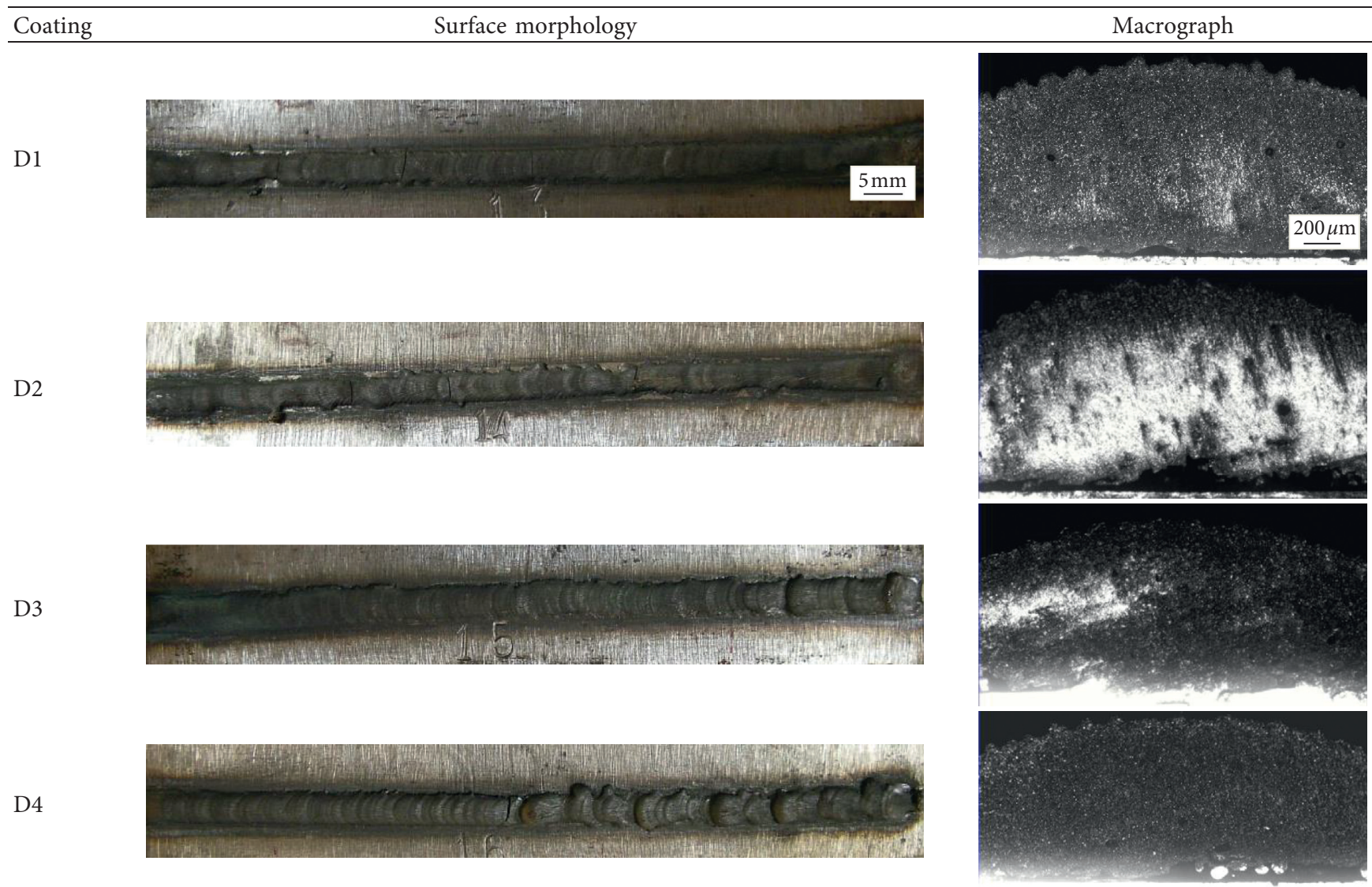


pitting on the surface, but the surface presents cracks. In addition, group $D$ coatings also have a peeling phenomenon and its height is not steady.

$$
P_{w}=\frac{P \cdot t}{S} .
$$

The experiment used the laser beam wattage density parameters as the general parameters of all other technical parameters such as laser beam power and scanning speed and surveyed the influence of power density with the coating formation. In the LC process, the laser energy density is a very important parameter, which characterizes the wattage magnitude of an area unit containing laser points. Different power densities on the material's surface will have different effects, thereby affecting the laser's absorption of the material [38].

In the abovementioned equation, $P_{\mathrm{w}}$ is the laser energy density (kW.s/ $\left.\mathrm{cm}^{2}\right) ; P$ is the laser beam power $(\mathrm{kW}) ; t$ is the duration of the laser action within a laser point $(s)$; and $S$ is the laser spot area $\left(\mathrm{cm}^{2}\right)$. It is possible to treat laser points as circles; thus,

$$
\begin{aligned}
& t=\frac{D}{v_{s}} \\
& S=\pi\left(\frac{D}{2}\right)^{2} .
\end{aligned}
$$

Here, $D$ is the laser point diameter $(\mathrm{mm})$ and $v_{s}$ is the laser scanning speed $(\mathrm{mm} / \mathrm{s})$; substituting formula (2) and (3) into (1), we get

$$
P_{w}=k \frac{P}{D \cdot v_{s}} \quad \text { with } \mathrm{k}=1.27 .
$$

The specific laser energy density is shown in Table 2. The laser energy density is determined by the laser power and the size of a laser spot. Typically, the higher the laser power, the harder it is to clad. Scanning speed and laser energy density will determine the temperature and heating time of laser energy. The laser energy density is determined by the degree of evaporation of the material:

(1) Under the irradiation of a laser beam which has a sufficient energy density, the surface of the powder material is heated to the melting point, so the material is melted, even evaporated.

(2) If the laser energy density is low and the scanning speed is fast enough, the metal will absorb the energy and only cause an increase in the temperature of the material surface. At this time, the depth of the molten lake at the swept point will be small, and the precoated powder layer cannot melt.

(3) If the laser energy density is too high and the scanning speed is low, the surface of the material will evaporate, instead of melting in the molten lake. Therefore, inconsistent laser energy density and scanning speed may cause uneven microstructure and affect the coating quality. Therefore, the choice of laser power plays a main role in the LC process.
Generally, with small laser power and high scanning speed, the cladding will have low shot temperature, short cladding time, and small cladding thickness.

With the appropriate combination of laser power and scanning speed, the thickness of the coating can be optimized. However, increasing the thickness of the cladding, its dilution rate decreases rapidly, and defects such as pitting, cracking, and peeling will appear in the coating.

Coating with high thermal stress and cracking are the two major shortcomings of the LC method; especially, cracks occur at the contiguous areas of the coating and the background material, leading to peeling of the coating. In fact, the crack is caused due to technical parameters, processing technology conditions, coating, substrate status, and other factors. Because the metal substrate and carbides are quite different in thermal parameters, in the crystallization process, the coating will shrink at a different level compared to the substrate, generating tensile stress. When the tensile stress is greater than the critical stress, the coating will show cracks.

Table 7 gives information about material properties of $\mathrm{TiC}, \mathrm{Co} 50$, and $\mathrm{H} 13$ tool steel. It can be seen that the material properties of the base alloy $\mathrm{Co}$ and the $\mathrm{H} 13$ steel are quite similar, whereas the opposite is true for TiC. Looking at the detail, the coefficient of thermal expansion of base alloy Co and H13 steel are quite similar, which is very beneficial for minimizing thermal stress and cracking formation. Similarly, the melting point of these two materials is approximately the same, so it can reduce the thinness, preserve metal bonding, and help prevent the coating surface from being rough, porous, and contaminated. In terms of $\mathrm{TiC}$, it has a very small coefficient of thermal expansion $\left(7.4 \times 10^{-6} /\right.$ ${ }^{\circ} \mathrm{C}$ ), but the elastic module is high and the melting point is also higher than Co. When projecting a laser beam, the area of the molten material has a very high temperature gradient, thus creating large thermal stress, facilitating the crack formation and peeling. Because the substrate and the coating have different mechanical properties, in addition to the very fast heating and cooling speed of the laser beam, the thermal stress generating in the coating is large.

Because the surface of the melting zone has a high temperature gradient, the surface tension is enormous. This surface tension causes the inner melting zone to have a strong convection phenomenon. The convection phenomenon of the liquid state metal in the melting zone will determine the uniformity of chemical composition in the coating, whose laser beam energy distribution characteristic has a great influence on the convection phenomenon. Therefore, the characteristic distribution of laser beam energy is an important factor determining the uniformity of chemical composition in the coating (Figure 3).

\subsection{Microstructure of the Heat-Affected Zone and Bonding} Characteristics of the Cladding. Figure 4 illustrates the shape of the overlays A1 and B1 cladding. From top to bottom, the structure of the coating includes the coating $(\mathrm{CZ})$, bonding layer (BZ), heat-affected area (HAZ), and steel substrate (SUB). It can be seen that the HAZ is very narrow. This is the 
TABle 7: Material properties of TiC, Co, and H13 steel.

\begin{tabular}{lcccc}
\hline Material & Density $\left(\mathrm{g} / \mathrm{cm}^{3}\right)$ & Melting point $\left({ }^{\circ} \mathrm{C}\right)$ & Coefficient of thermal expansion $\left(\times 10^{-6} /{ }^{\circ} \mathrm{C}\right)$ & Modulus of elasticity $(\mathrm{GPa})$ \\
\hline TiC & 4.93 & 3147 & 7.4 & 460 \\
Co & 8.83 & 1492 & 12.5 & 219 \\
H13 steel & 7.80 & 1427 & 12.4 & 210 \\
\hline
\end{tabular}

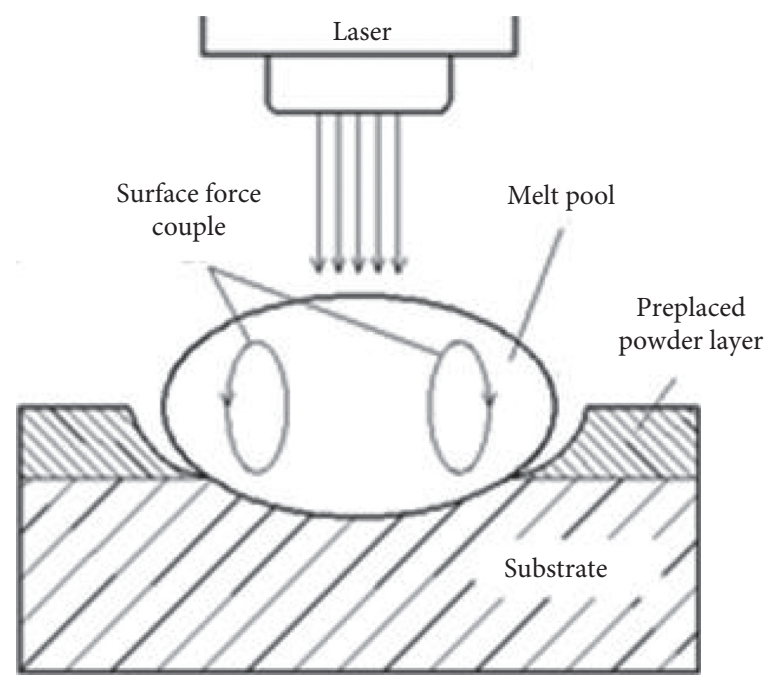

FIgURE 3: The diagrammatic sketch of the melt pool when the substrate slightly fuses.

outstanding advantage of the LC method. The reason is during the melting process, the laser accumulation is low, so the energy penetrating the substrate is very small. Figure 4(b) shows the heat-affected zone of B1 coating. The organized steel is martensite (H13steel), and after LC, it is found that the matrix does not undergo phase transformation due to the high-energy laser heating. The reason is that the substrate steel is affected by heat from the large energy source of the laser beam which causes the particle boundaries' moving and lead to large particles "swallowing" small particles. This process happens in a very short time. The result also shows that if the adjustment of technological parameters is not appropriate, it is easy for the thermal stresses to appear, thereby generating cracks and affecting product quality. Therefore, in the LC method, the determination of technology parameters is very important. The width of the heataffected zone of the laser sample was measured with a metallographic microscope, and it was found that the width of the heat-affected zone decreased as the laser scanning speed increased. The size of the substrate heat-affected zone is related to the energy of the laser input substrate and the thermal deposition depth density. When the laser input power is increased or the scanning speed is reduced, the specific energy of the laser is increased, and the specific energy required to melt the powder is constant. The increased specific energy is absorbed by the matrix, and therefore, the width of the heat-affected zone is increased. During LC, if the process parameters are not properly matched, cracks are likely to occur due to thermal stress and tissue stress, which affects the quality of the parts, such as the
A1-coated substrate (Figure 4(a)). The residual stress of the LC layer is the main reason for its cracking. This residual stress mainly comes from three aspects: thermal stress, phase transformation stress, and restraint stress. Because there is not enough liquid metal to supplement the LC and solidification process, it is bound by the surrounding colder substrate during the subsequent solid cooling shrinkage process, which causes these stresses to be difficult to be released. Once released, it will cause cracks. Among these three kinds of stress, due to the characteristics of LC quenching and heating, the influence of thermal stress is the most obvious.

Figure 5 shows the elements line scanning spectra of A2 coating and B4 coating. It can be seen that, with the constant capacity, the further away from the link, the higher the concentration of the elements $\mathrm{Co}, \mathrm{Cr}, \mathrm{Ni}$, and $\mathrm{W}$, while the content of Fe decreases significantly. This means that, during the melting process, there was quite a strong diffusion of $\mathrm{Fe}$ from the base steel to the coating, or in other words, it formed a stable metal-type bond between the coating and the steel substrate.

In addition, in the B1 coating, the energy spectrum analysis was also carried out at $35 \mu \mathrm{m}, 70 \mu \mathrm{m}$, and $140 \mu \mathrm{m}$ from the "white bright band." Table 8 shows the distribution of the main components of $\mathrm{Co}, \mathrm{Cr}, \mathrm{Ni}, \mathrm{W}$, and $\mathrm{Fe}$ in the $\mathrm{B}$ coating. It can be seen that, under the constant power refractive index, the farther away from the "white bright band", the content of alloying elements $\mathrm{Co}, \mathrm{Cr}, \mathrm{Ni}$, and $\mathrm{W}$ in the coating increases, while the $\mathrm{Fe}$ content decreases. It shows that, during the LC process, the elements on the 


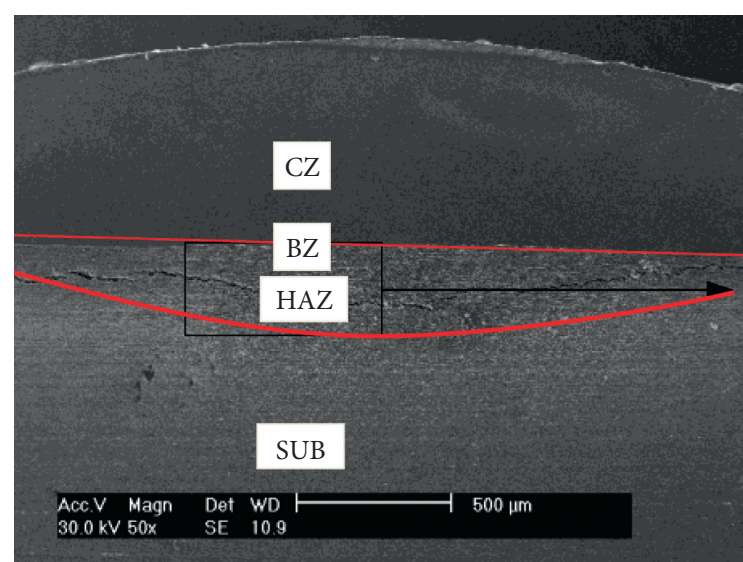

(a)

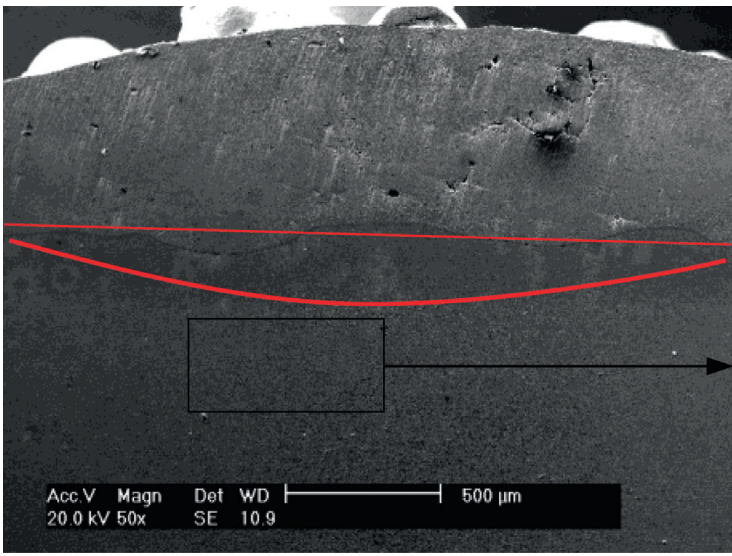

(c)

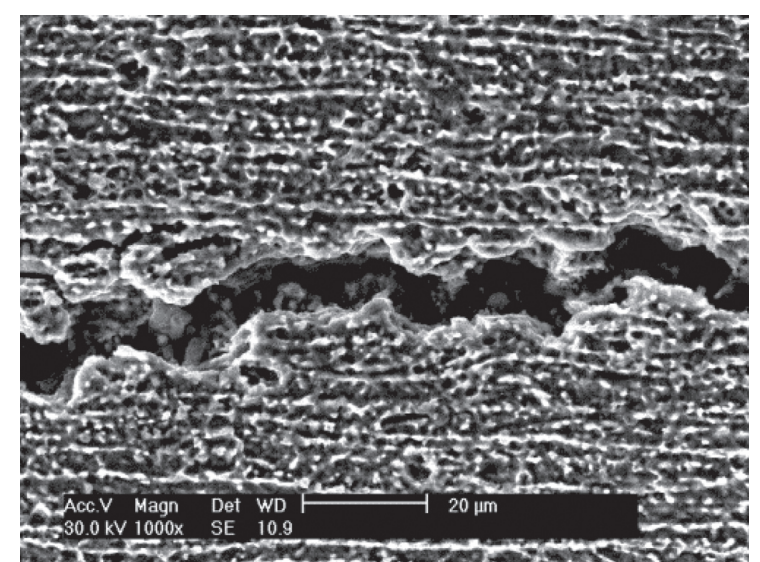

(b)

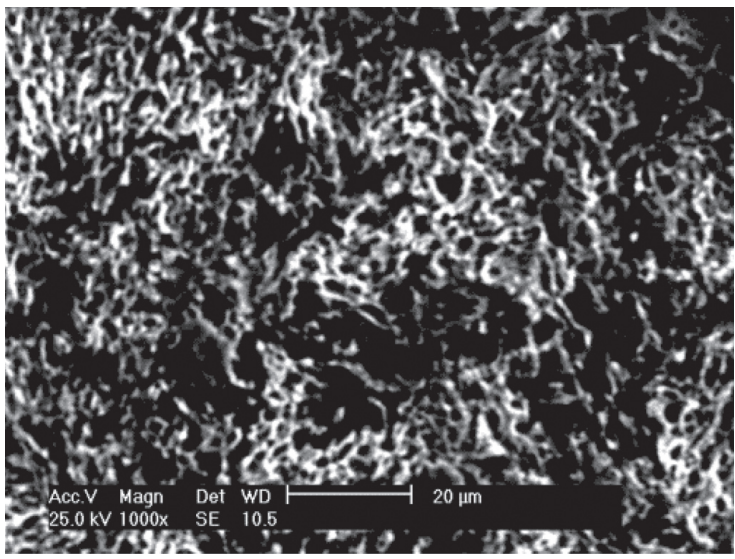

(d)

FIGURE 4: SEM of the A1 and B1 coating from the transverse cross section and heat-affected zone: (a) and (b) A1 coating; (c) and (d) B1 coating.

surface of the coating and the substrate diffused together, so that a good crystalline bond is formed between the coating and the H13 steel substrate. This is extremely beneficial to improve the bonding characteristics of the coating and the substrate and improve the mechanical properties of $\mathrm{H} 13$ steel.

3.3. The Cross-Section Geometry of the Cladding. Based on the analysis results of the macroscopic morphology, the samples with the same composition are selected from each group for analysis. The corresponding sample numbers are shown in Table 9.

Figure 6 demonstrates the microstructure of A, B, C, and $\mathrm{D}$ coatings. It can be seen that the coating and the substrate interface show a clear "white bright band," showing that the coating and the H13 steel substrate can achieve a good metallurgical bond. In A coating, the "bright band" is a quite flat-growth tissue. In C coating with $20 \% \mathrm{TiC}$, the "white bright band" contains a large amount of black TiC particles. When the $\mathrm{TiC}$ content in the preset layer was increased to $30 \%$, the D coating did not achieve a good combination with the substrate. The reason is the thermal expansion coefficients of TiC powders and Co-based alloy powders are quite dissimilar. Consequently, when the temperature gradient increases, the thermal stress and the formation of cracks generated by expansion increase. In addition, the required laser energy density is related to the melting point, when the absorption rate is high, and the required laser energy density is greater. Studies by Si $[39,40]$ found that if the content of added carbide reinforcing phase is too high, the brittleness of the coating will experience a significantly increased. This is because of the formation of a large amount of carbides, leading to the coating being prone to cracks and spalling during working operation.

It can also be seen that the microstructure density of the A sample is good, and a good metallurgical bond is achieved between the coating and the substrate. The composite coating $\mathrm{A}, \mathrm{B}$, and $\mathrm{C}$ samples can clearly distinguish the cladding zone, bonding zone, and heat-affected zone. A good metallurgical bond is formed between the coating and the substrate. The microstructure density of the $\mathrm{C}$ sample is better than that of the $B$ sample. The $D$ coating and the substrate are not well bonded, which is attributed to the high TiC content in the coating. According to the geometry of the composite coating, it can be analyzed that increasing the number of carbides is beneficial to enhance the strengthening effect, but excessive $\mathrm{TiC}$ content is often beneficial to 

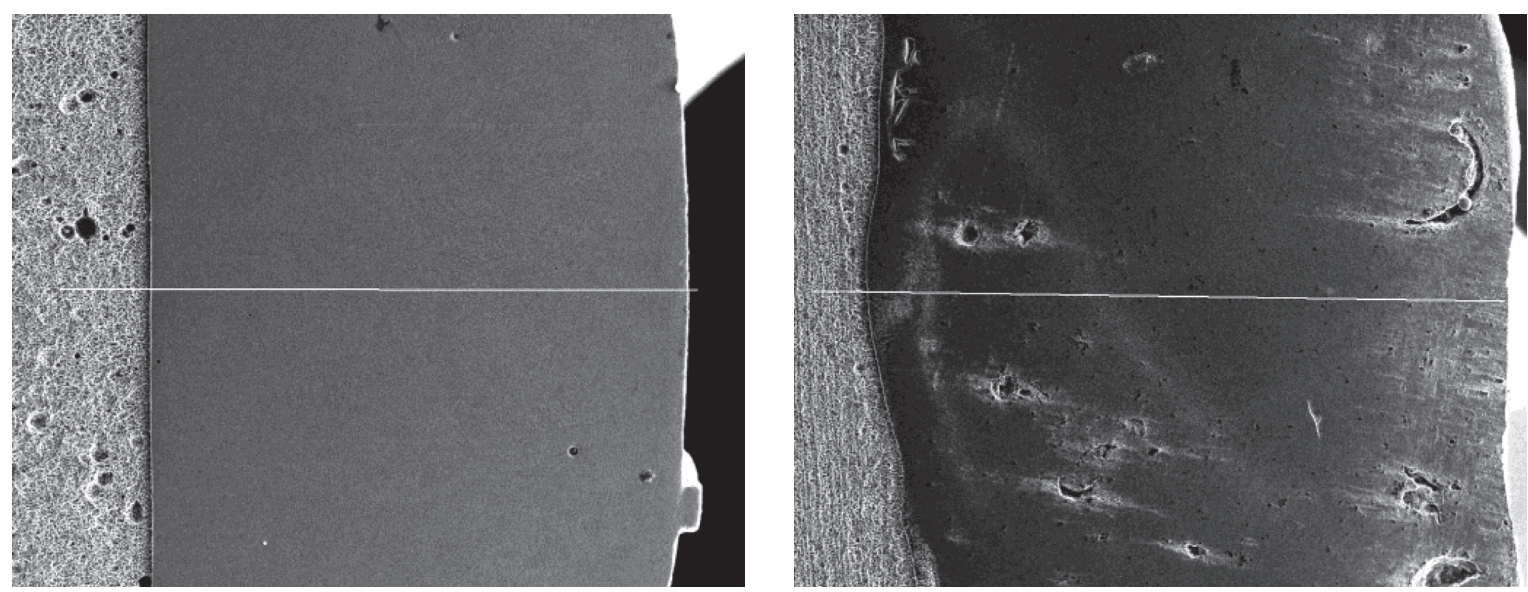

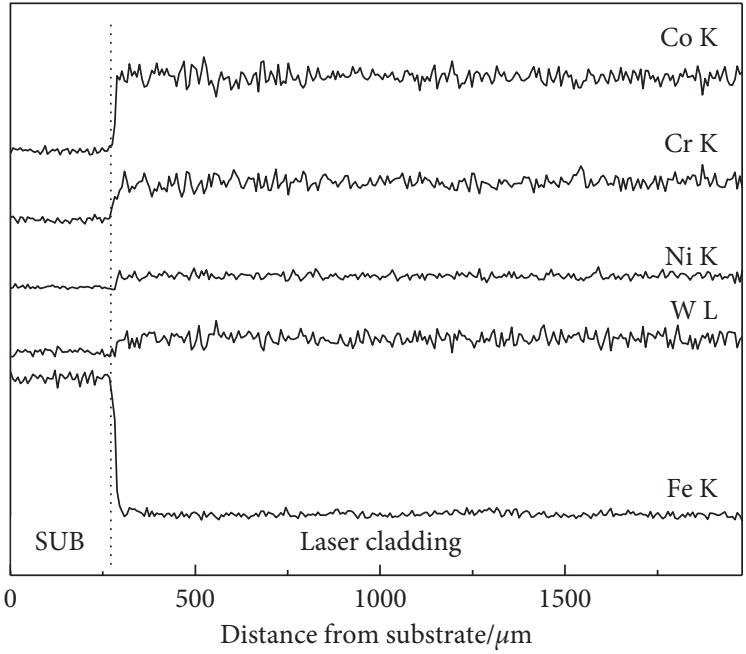

(a)

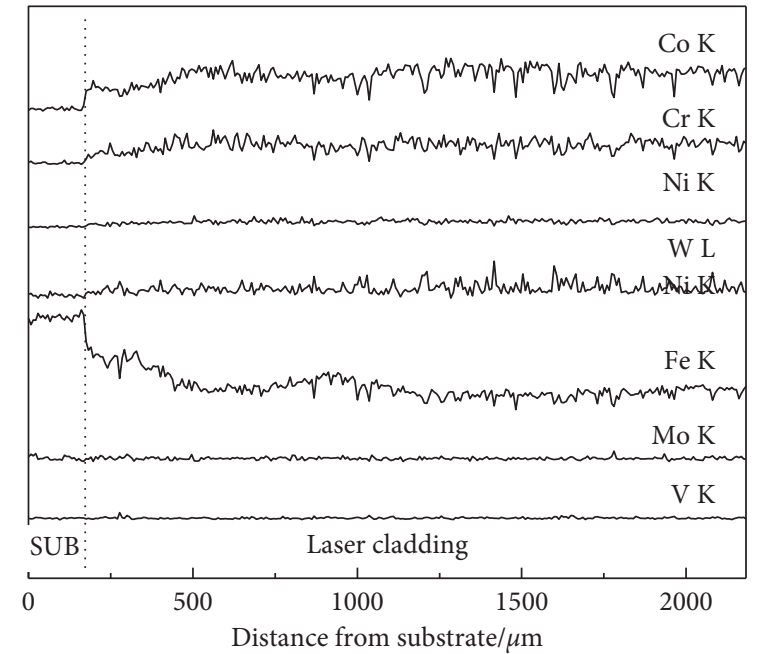

(b)

Figure 5: Elements line scanning spectra: (a) A2 coating; (b) B4 coating.

TABLE 8: EDS analysis for $\mathrm{Co}, \mathrm{Cr}, \mathrm{Ni}, \mathrm{W}$, and $\mathrm{Fe}$ of $\mathrm{B} 1$ coating.

\begin{tabular}{lccrrr}
\hline \multirow{2}{*}{ Distance from the interface $(\mu \mathrm{m})$} & \multicolumn{3}{c}{ Element contents (wt.\%) } & $\mathrm{W}$ & $\mathrm{Ni}$ \\
\hline 35 & $\mathrm{Cr}$ & $\mathrm{Co}$ & 25.75 & 3.32 & 6.08 \\
70 & 18.52 & 34.96 & 4.92 & 6.70 & 22.34 \\
140 & 24.03 & 36.67 & 5.26 & 8.38 & 14.88 \\
\hline
\end{tabular}

TABle 9: Preparation parameters and the corresponding sample numbers.

\begin{tabular}{lcccc}
\hline Coatings & Composition ratios, $r_{\mathrm{m}}(\mathrm{Co} 50: \mathrm{TiC})$ & Laser power, $\mathrm{P} / \mathrm{kW}$ & Scanning speed, $v_{s}(\mathrm{~mm} / \mathrm{min})$ & Laser energy density, $P_{\mathrm{w}} /\left(\mathrm{kW} . \mathrm{s} / \mathrm{cm}^{2}\right)$ \\
\hline A (A2) & $1: 0$ & 3.3 & 400 & 12.57 \\
B (B4) & $9: 1$ & 3.6 & 500 & 10.97 \\
C (C1) & $4: 1$ & 3.9 & 350 & 16.98 \\
D (D1) & $7: 3$ & 350 & 18.29 \\
\hline
\end{tabular}

the formation of bulk carbides (eutectic and secondary precipitation), which makes the coating brittle increase. Generally, the total amount of carbides cannot be too large, so the degree of strengthening is limited. The research by Chen et al. [41] has shown that the content of carbides has an important effect and usually has an optimal value (about 30 vol.\%). When the content increases or decreases, the wear resistance will decrease.

Figure 7 illustrates the microstructure of the cross section of $\mathrm{B}, \mathrm{C}$, and $\mathrm{D}$ coating samples. In $\mathrm{A}$ coating, the 


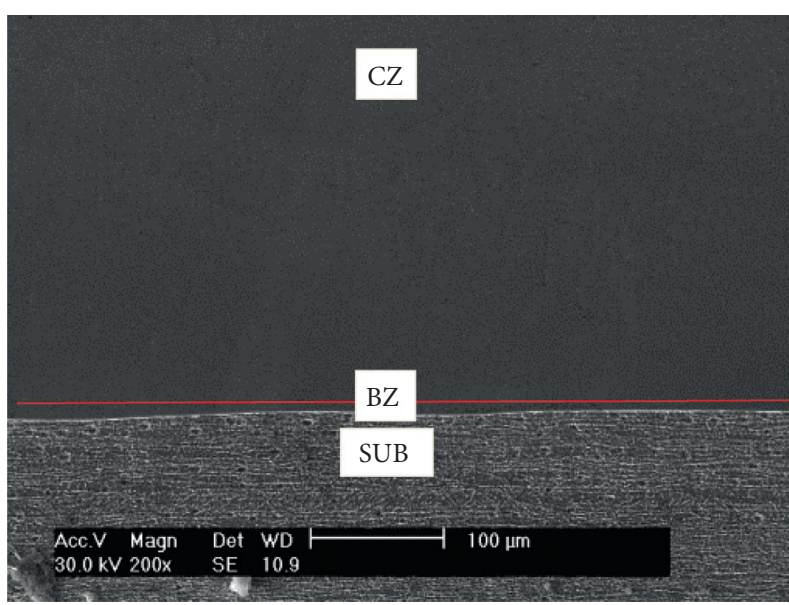

(a)

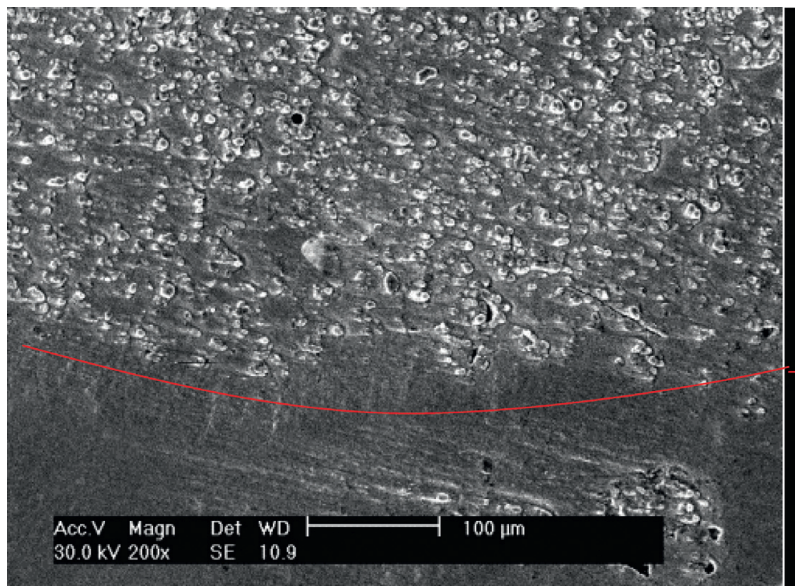

(c)

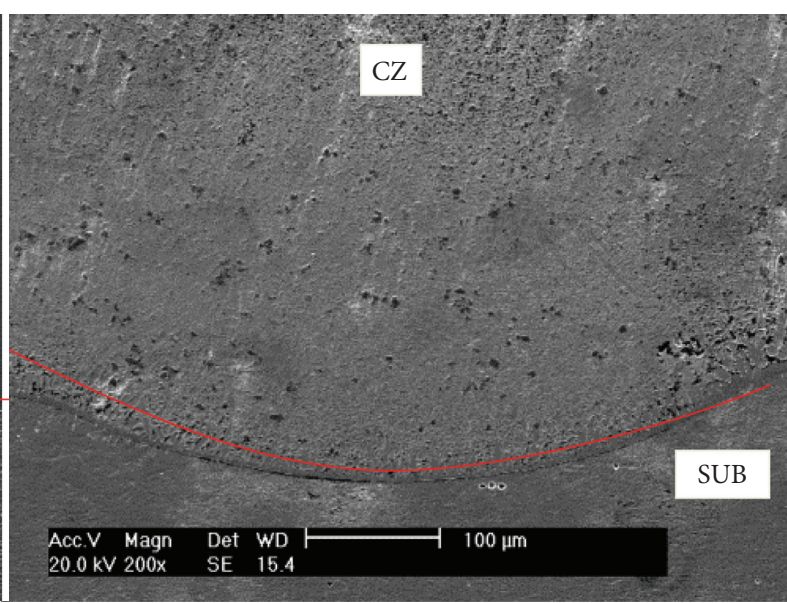

(b)

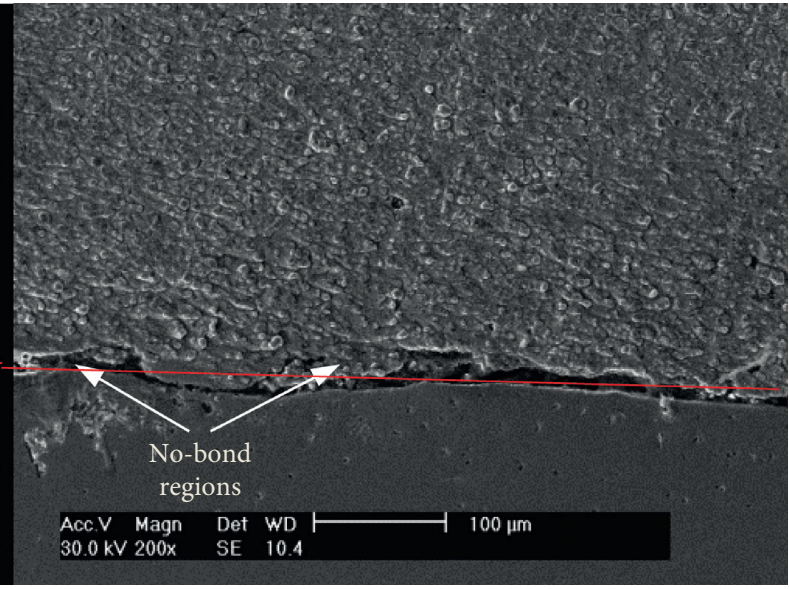

(d)

FIgure 6: Microstructure of coatings: (a) A coating, (b) B coating, (c) C coating, and (d) D coating.

dendrite structure of the coating gradually disappeared from the bottom to the surface, and it turned into a large number of dense fine structures near the coating surface. The A coating has obvious growth characteristics of columnar dendrites and equiaxed crystals and solidifies and develops towards the coating surface perpendicular to the bonding zone. Compared with the microstructure of the A coating, the structure of the $\mathrm{B}$ coating is no longer composed of neat columnar dendrites, and there is no obvious direction of dendrite growth. Many interdendritic eutectic structures exist. In addition, it can be seen that the structure of the B coating is composed of bright white dendrites, eutectics between the dendrites, and black TiC particles, and the $\mathrm{TiC}$ particles are diffusely distributed, which can play a good hardening role. In C coating with $20 \% \mathrm{TiC}$, with the increase in the amount of $\mathrm{TiC}$ in the preset layer, the content of the $\mathrm{TiC}$ reinforcing phase and the phase structure of the coating evolve accordingly. The coating is also composed of bright white dendrites, eutectics between the dendrites, and black TiC particles. While the size of the $\mathrm{TiC}$ particles in the structure increases, the number decreases slightly. The resulting $\mathrm{TiC}$ is evenly distributed in the coating. When the TiC content in the preset layer was increased to $30 \%$, the $\mathrm{D}$ coating did not achieve a good combination with the substrate. The figure points out that $\mathrm{TiC}$ exists like a large number of diffusely distributed spherical structures.

Figure 8 shows the microstructure from the bottom zone to the upper zone of $\mathrm{B}, \mathrm{C}$, and $\mathrm{D}$ cladding. It can be seen that the morphology of $\mathrm{TiC}$ is mainly spherical. The morphology of $\mathrm{TiC}$ in the $\mathrm{B}$ coating structure is different due to its different parts in the molten pool, and its composition, temperature distribution, and cooling rate are different. TiC in the middle and the surface of the coating is a large block structure, while the bottom of the coating has a low temperature and insufficient melting, and due to the rapid heat transfer effect of the cold matrix, the cooling rate is large, and the $\mathrm{TiC}$ grains are too late. It has stopped growing when it is large, so a fine granular structure is formed. C cladding demonstrates that $\mathrm{TiC}$ has the form of "cross flower" and "twigs" in the bottom zone [42-44]. In the middle zone and upper zone, $\mathrm{TiC}$ mostly exists in a spherical shape. In particular, the size of the $\mathrm{TiC}$ rises steadily from the bottom zone to the surface of the cladding. In the $\mathrm{D}$ cladding, TiC 


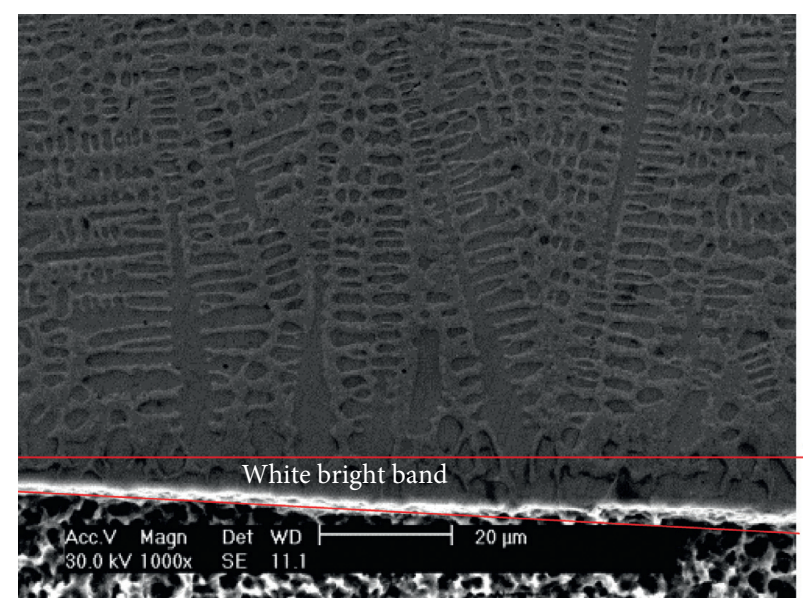

(a)

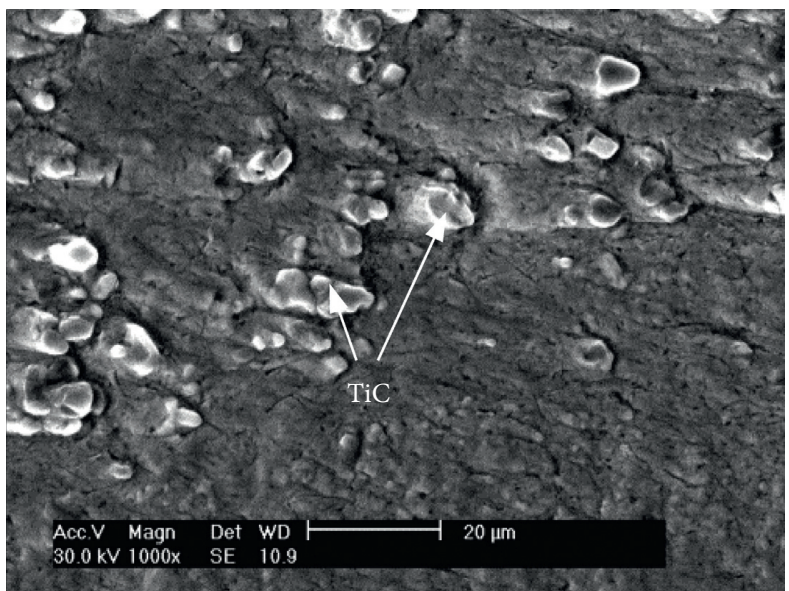

(c)

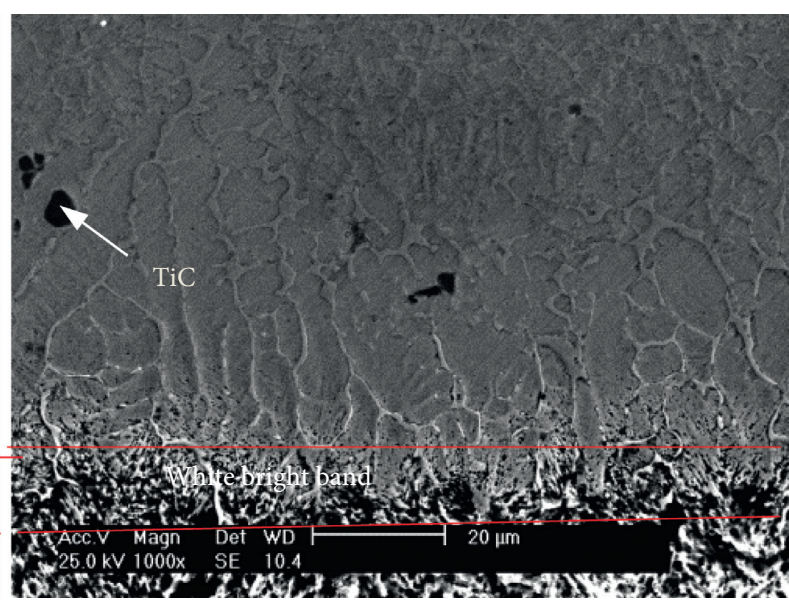

(b)

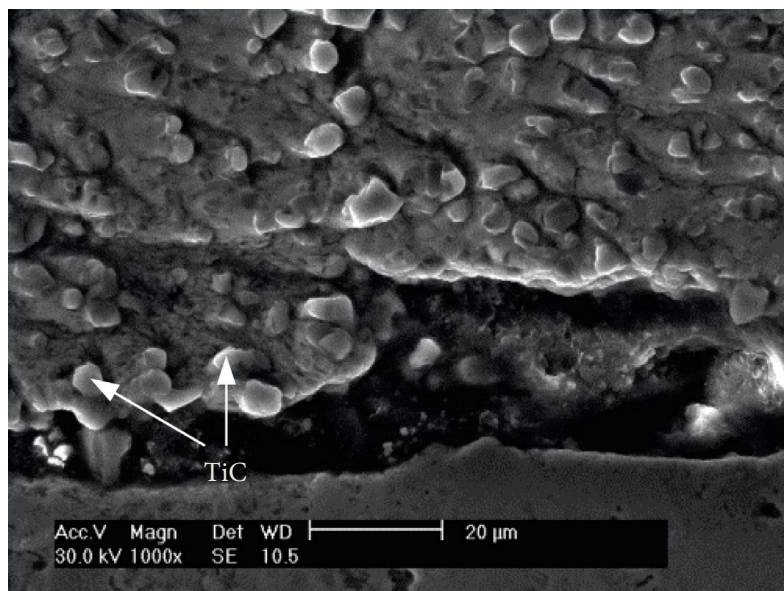

(d)

FiguRE 7: Microstructure of the cross section of the coatings after the laser cladding process. (a) A coating, (b) B coating, (c) C coating, and (d) D coating.
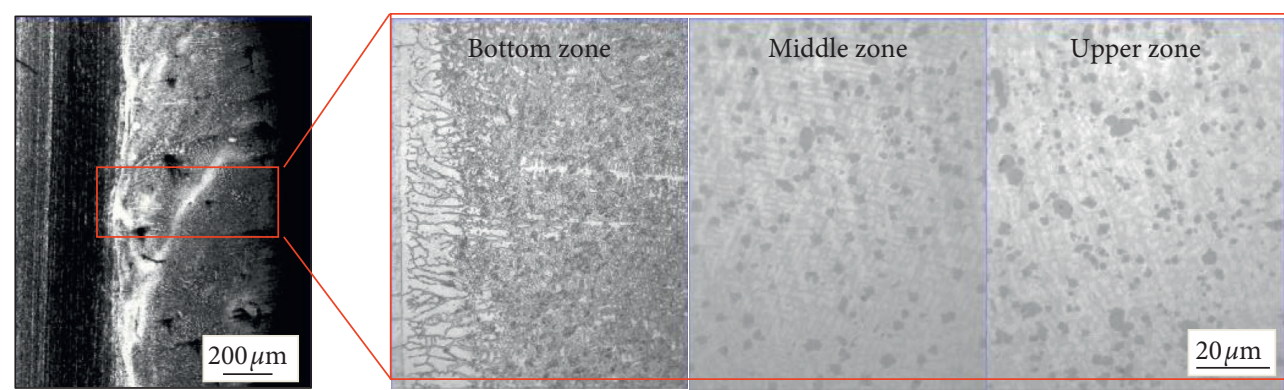

(a)

Figure 8: Continued. 

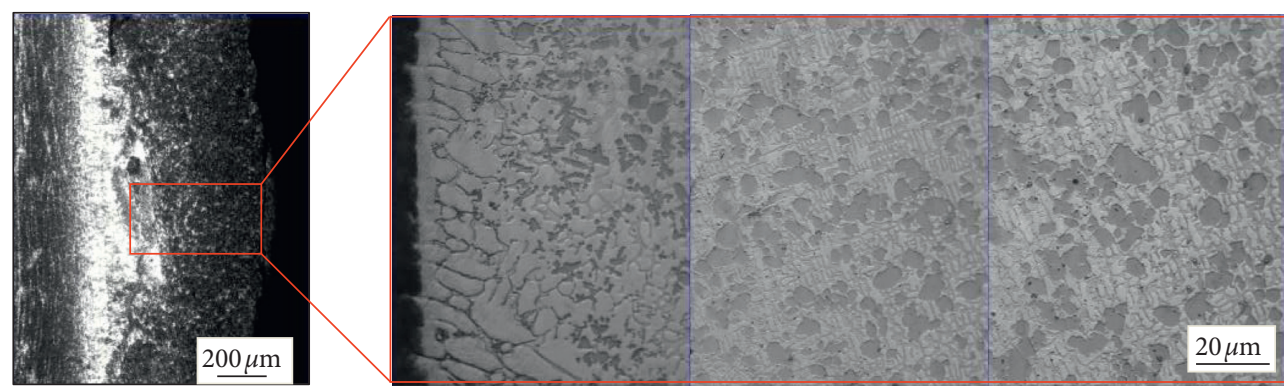

(b)
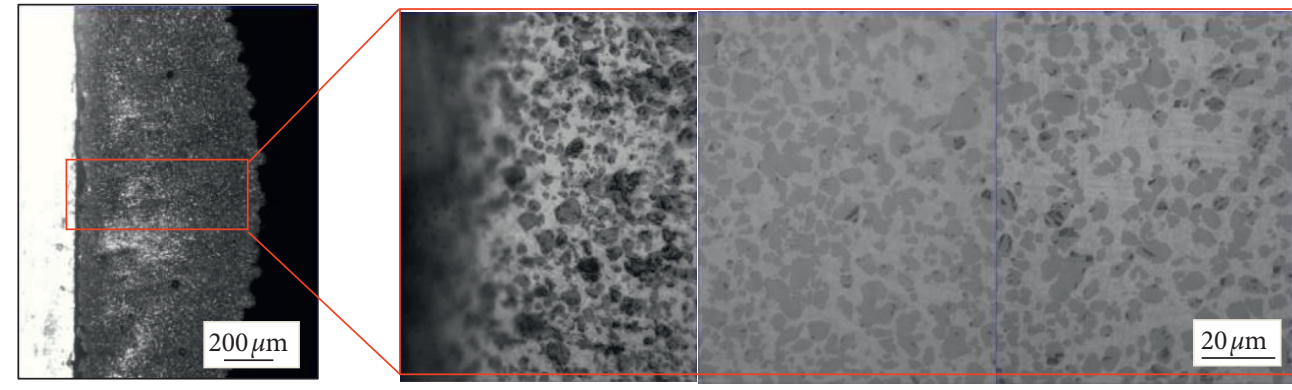

(c)

Figure 8: Microstructure of the Co50/TiC claddings: (a) B cladding, (b) C cladding, and (c) D cladding.

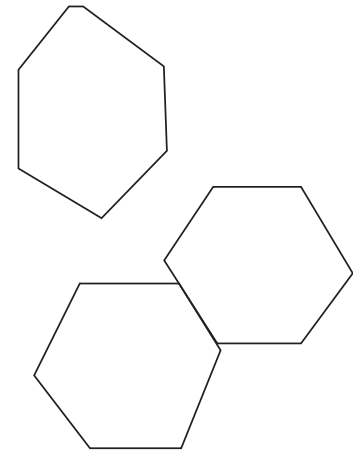

(a)

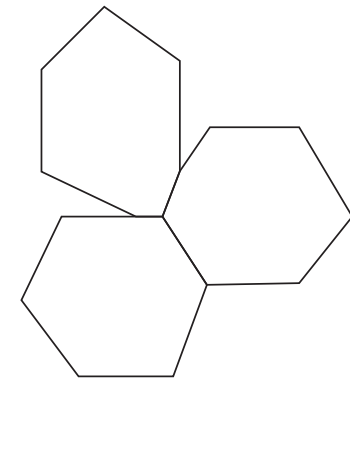

(b)

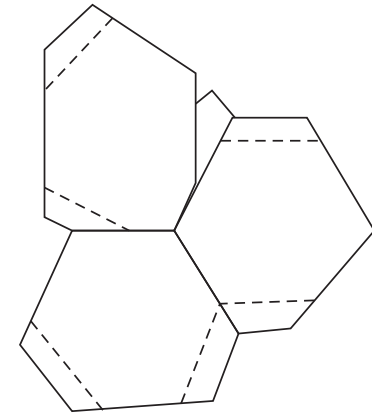

(c)

FIgURE 9: Schematic illustration of TiC collision and sintering within Co alloy melt: (a) a stuck TiC moving at faster speed v2 catching up a single TiC; (b) collision with each other; (c) partial sintering among TiC particles and growth of the whole cluster.

exhibits like a large number of diffusely distributed spherical structures. Unlike C coating, TiC particle size in D coating has no clear gradient change.

Pei [14] studied the gradient change law of TiC particle size and the gradient change law of $\mathrm{TiC}$ volume content. The results of statistical analysis showed that the average diameter of TiC particles gradually increased about $0.8 \mu \mathrm{m}$ to $4.5 \mu \mathrm{m}$ from the bottom to the upper zone of the cladding. The change of the particle size is significant and continuous; the average diameter of TiC particles $\left(S_{\mathrm{p}}\right)$ and the distance $(\mathrm{d})$ from the bonding zone are in a quadratic function relationship $S_{p}=0.8+1.22 \times 10^{-2} d$ $-10^{-5} d^{2}$. The study also found that although the spacing between $\mathrm{TiC}$ particles in the cladding increases slowly with its distribution position upwards, the volume content of TiC still shows a certain gradient growth law along the thickness direction, about $4 \%$ at the bottom to $33 \%$ at the upper zone. According to Stokes' law, in Co alloy melting, the floating speed of TiC particles with different sizes is different. Because the larger TiC particles rise faster than the smaller ones, it results in selective capture of TiC particles. That is, small particles with a slower moving speed are always captured first. On the other hand, the melt shear caused by strong convection in the laser molten pool also promotes collisions between particles. After the $\mathrm{TiC}$ particles collide together, their growth and bonding characteristics will be mainly controlled by the time they exist in the melt (Figure 9). In the rapid solidification process of the laser molten pool, the melting and bonding of the particles are usually difficult to complete. Li and Chen et al. [45] have shown that the $\mathrm{TiC}$ morphology in the coating structure is different due to its different parts of the molten pool (the composition, 
temperature gradient, and cooling rate are different). The different morphologies of $\mathrm{TiC}$ in different regions are caused by different cooling rates.

\section{Conclusions}

In $10 \% \mathrm{TiC}$ coating, the "bright band" is a quite flatgrowth tissue. In the coating with $20 \% \mathrm{TiC}$, the "white bright band" contains a large amount of black TiC particles. When the TiC content in the preset layer was increased to $30 \%$, the coating did not achieve a good combination with the substrate. The microstructure density of the Co50 sample is good, and a good metallurgical bond is achieved between the coating and the substrate. The composite coating Co50, 10\% TiC, and $20 \% \mathrm{TiC}$ samples can clearly distinguish the cladding zone, bonding zone, and heat-affected zone. The microstructure density of the $20 \% \mathrm{TiC}$ sample is better than the $10 \% \mathrm{TiC}$ sample. The $30 \% \mathrm{TiC}$ coating and the substrate are not well bonded, which is attributed to the high $\mathrm{TiC}$ content in the coating.

Co50 coatings have the characteristic bright white color, when adding $\mathrm{TiC}$, and with the increase in $\mathrm{TiC}$ ratio, the quality of coating surface also increases. Co50 coatings have a relatively smooth surface, the surface is relatively smooth, and the two side edges are also quite smooth. $10 \% \mathrm{TiC}$ coatings have a poor surface quality, a spraying material phenomenon on 2 side edges which is quite serious, and a lot of porosity on the surface of the coating. $20 \% \mathrm{TiC}$ has better quality than $10 \% \mathrm{TiC}$, with no cracks, but the coatings have a large undulating level and the flatness of the coatings is quite low. $30 \% \mathrm{TiC}$ has the best surface morphology, but the surface exhibits cracks.

$10 \% \mathrm{TiC}$ coating includes the original $\mathrm{TiC}$ particles that are not fully melted, and there are also primary $\mathrm{TiC}$ particles that are precipitated in situ from the liquid phase during solidification. 20\% TiC coating indicates a large amount of $\mathrm{TiC}$ in the form of cross petals and twigs. In the middle part and upper part, TiC mostly exists in a spherical shape. In the $30 \% \mathrm{TiC}$ sample coating, the figure points out that $\mathrm{TiC}$ exists like a large number of diffusely distributed spherical structures.

The coatings of TiC/Co composite with less than 20\% TiC showed good metallurgical bonding characteristics with the H13 steel surface.

The coatings of Co-based composite with $20 \% \mathrm{TiC}$ represent good comprehensive properties, satisfying the requirements of production.

\section{Data Availability}

The data used to support the findings of this study are available upon request to the author.

\section{Conflicts of Interest}

The author declares that there are no conflicts of interest regarding the publication of this paper.

\section{Acknowledgments}

The author acknowledges Kunming University of Technology, HCMC University of Technology and Education, and Material Testing Laboratory (HCMUTE). They gave the author an opportunity to join their team and accessed the laboratory and research machines. Without their appreciated support, it would not have been possible to conduct this research.

\section{References}

[1] C. Xiang-Hong, S.-Q. Wang, Q.-C. Jiang et al., "Application and failure analysis for cast hot-working die," Heat Reatment Of Metals, vol. 1, pp. 17-18, 2001.

[2] G. Antonio, M. Roberto, R. Maria et al., "Alloys for aeronautic applications: state of the art and perspectives," Metals, vol. 9, no. 6, p. 662, 2019.

[3] J. P. Hardro, Development of materials for the rapid manufacture of die cast tooling, PhD Dissertation, Newport: University of Rhode Island, Newport, RI, USA, 2001.

[4] M. Saverio, G. Antonio, I. Giovanni et al., "A further analysis on Ti6Al4V lattice structures manufactured by selective laser melting," Journal of Healthcare Engineering, vol. 2019, Article ID 3212594, 9 pages, 2019.

[5] X. Q. Cao, H. Y. He, S. S. Zhou et al., "Microstructure and property analysis of laser cladded Ni60A alloy on H13 steel surface," Journal of Taiyuan University of Technology, vol. 41, no. 4, pp. 360-363, 2010.

[6] H. He, Experimental Study on Laser Cladding of Ni-Based and Co-based Alloy Powders on the Surface of H13 Steel, Master Degree Thesis, Taiyuan University of Technology, Taiyuan, China, 2010.

[7] W. Zhang, S. Shi, Y. Chen et al., "Research on microstructure and property of Ni-WC composite material made by laser cladding," Applied Laser, vol. 32, no. 1, pp. 18-21, 2012.

[8] G. Shao-Yi, Li Xing-Jun, Y. Qiu-He et al., "Microstructure and tribological properties of laser clad WC-Ni/TiC composite coatings," Journal of Materials Engineering, vol. 6, pp. 72-75, 2008.

[9] X. Liu, "Microstructure evolution of laser cladding with feeding powder for Co-based alloy in addition with WC in reheating and cooling process," Rare Metal Materials and Engineering, vol. 36, no. 4, pp. 621-624, 2007.

[10] C. Chen, H. Yu, Y. Hou et al., "Laser cladding WC/Co cermet on 45 steel surface," Journal of Ceramics, vol. 19, no. 3, pp. 137-143, 1998.

[11] Y. Li, X. Peng, Q. Chen et al., "Wear resistance of WC-Co coatings dealt with laser cladding," Applied Laser, vol. 29, no. 2, pp. 108-111, 2009.

[12] B. Xu, H. Shi, and X. Zhang, "Effect of double-layer precoating on the laser cladding ceramal layer," Chinese Journal of Lasers, vol. A25, no. 8, pp. 763-767, 1998.

[13] Y. Wu, P. Lin, Z. Wang et al., "Research on gradient coating of TiC/Ni by plasma cladding with multi-pre-placed layer," 
Transactions of Materials And Heat Treatment, vol. 25, no. 3, pp. 74-77, 2004.

[14] Y. Pei, "Laser clad TiCp/Ni alloy functionally gradient coating and its in-situ formation mechanism," Acta Metallurgica Sinica, vol. 34, no. 9, pp. 987-991, 1998.

[15] S. Yang, N. Chen, W. Liu et al., "Fabrication of Ni composite coatings reinforced with $\mathrm{TiC}$ particles by laser cladding," Surface and Coatings Technology, vol. 183, no. 2-3, pp. 254260, 2004.

[16] L. Qiang and T. Fu, "Study on porosity of Ni60 + WC coating by laser-clad," Laser Journal, vol. 27, no. 3, pp. 61-62, 2006.

[17] Y. Chen, M. Zhong, W. Liu et al., "Porosity investigation in laser cladding WC/Co cemented carbide with powder feeding," Transactions of Metal Heat Treatment, vol. 23, no. 2, pp. 49-53, 2002.

[18] Y. Xiong, Y. Wang, K.-F. Zhang et al., "Microstructures and properties of laser cladding Stellite6/WC," China Surface Engineering, vol. 21, no. 1, pp. 37-40, 2008.

[19] Z. Xiao-Wei, C. Ming-Ju, and K. Yang, "Effect of Al2O3 on the microstructure and wear properties of laser-clad Ni60 alloy coatings," Laser Journal, vol. 27, no. 5, pp. 81-83, 2006.

[20] J. Xiang, G. Li, Y. Xu et al., "Effect of Al2O3 on the wear resistance of Ni-based alloys coating by laser cladding," Heat Treatment Technology and Equipment, vol. 30, no. 4, pp. 6-10, 2009.

[21] L. Ming-Xi, L. Hui-Sheng, Y. Xiao-Min et al., "Effect of nano$\mathrm{Al} 2 \mathrm{O} 3$ on microstructure of Co based alloy coating by laser cladding," Transactions of The China Welding Institution, vol. 26, no. 6, pp. 36-39, 2005.

[22] M. Ma, Y. Liu, Y. Gu et al., "Synthesis of AlxCoCrNiMo high entropy alloy coatings by laser cladding," Applied Laser, vol. 6, pp. 433-437, 2010.

[23] J. Zhao and Z. He, "Research on status of cracking in laser cladding layer," New Technology \& New Process, vol. 10, pp. 58-61, 2011.

[24] X. Wang and H. Qi, "Synthetic experiment study and theorematic analysis of crack control of thick laser cladding layer," Journal of Nanhua University (Science \& Engineering), vol. 15, no. 3, pp. 36-55, 2001.

[25] S. Shi, "The effect of laser cladding process and powder on the cracking behavior of the coating," Surface Technology, vol. 27, no. 4, pp. 27-29, 1998.

[26] I. Hemmati, V. Ocelík, and J. T. M. De Hosson, "Dilution effects in laser cladding of Ni-Cr-B-Si-C hardfacing alloys," Materials Letters, vol. 84, no. 1, pp. 69-72, 2012.

[27] Y. F. Hou, S. T. Gu, Y. M. Bao et al., "Measurement and numerical simulation of mechanical properties for laser clad H13-TiC composite coatings," Light Industry Machinery, vol. 29, no. 4, pp. 87-91, 2011.

[28] T. Xiaodan, Y. Jianhua, K. Fanzhi et al., "Manufacture and microstructure performance of $\mathrm{H} 13$-TiC gradient composite coating made by laser cladding," Laser Technology, vol. 3, pp. 326-330, 2010.

[29] S. Zhang, C. Zhang, Z. Wen et al., "Microstructure and performance of a laser clad co-based alloy," Rare Metal Materials and Engineering, vol. 30, no. 3, pp. 220-223, 2001.

[30] M. Li, Y. He, and G. Sun, "Microstructure of wide/narrow band beam laser cladding CO-based alloy on Ni base superalloy/45\# steel," Chinese Journal of Lasers, vol. 30, no. 11, pp. 1044-1048, 2003.

[31] S. I. Songhua, Y. He, X. Yuan et al., "Microstructure and wearresistance of laser clad Co-based alloy coatings with B4Cp and SiCp," The Chinese Journal of Nonferrous Metals, vol. 13, no. 2, pp. 454-459, 2003.
[32] A. Emamian, S. F. Corbin, and A. Khajepour, "Tribology characteristics of in-situ laser deposition of Fe-TiC," Surface and Coatings Technology, vol. 206, no. 22, pp. 4495-4501, 2012.

[33] A. Emamian, S. F. Corbin, and A. Khajepour, "Effect of laser cladding process parameters on clad quality and in-situ formed microstructure of Fe-TiC composite coatings," Surface and Coatings Technology, vol. 205, no. 7, pp. 2007-2015, 2010.

[34] Z. Huang, Q. Cai, J. Niu et al., "Research progress of iron and steel material strengthened by particle," Hot Working Technology, vol. 40, no. 8, pp. 79-83, 2011.

[35] Y. Yan, W. Bokang, H. Lin et al., "Effect of chemical composition on microstructure and property of in-situ $\mathrm{TiCp} / \mathrm{Fe}$ composites," The Chinese Journal of Nonferrous Metals, vol. 9, no. 2, pp. 225-230, 1999.

[36] V. K. Acker, D. Vanhoyweghen, R. Persoons et al., "Influence of tungsten carbide particle size and distribution on the wear resistance of laser clad WC/Ni coatings," Wear, vol. 258, no. 14, pp. 194-202, 2005.

[37] E. O. Correa, J. N. Santos, and A. N. Klein, "Microstructure and mechanical properties of WC Ni-Si based cemented carbides developed by powder metallurgy," International Journal of Refractory Metals and Hard Materials, vol. 28, no. 5, pp. 572-575, 2010.

[38] X. Zhang, H. Liu, Y. Jiang et al., "Laser in situ synthesized TiN/ Ti3Al composite coatings," Acta Metallurgica Sinica, vol. 47, no. 8, pp. 1086-1093, 2011.

[39] S. Song-hua, K. Xu, Y. Xiao-min et al., "Microstructure and wear performance of laser cladding $\mathrm{Cr} 3 \mathrm{C} 2 / \mathrm{Co}$ alloy composite coating," Tribology, vol. 26, no. 2, pp. 125-129, 2006.

[40] S. Songhua, X. Yuan, X. Zuo et al., "Effect of B4C particles on microstructure and wear resistance of Co-based alloy laser cladding," Transactions of the China Welding Institution, vol. 25, no. 3, pp. 61-64, 2004.

[41] H. Chen, H. Zhao, X. Ma et al., "General situation of the use and development of wear-resistant materials in my country," in Proceedings of the China Special Steel Annual Conference 2005, Beijing, China, , 2005.

[42] C. Yao and H. Wang, "Microstructure of laser clad TiC/FeAl composite coating and growth mechanism of primary TiC carbide," Rare Metal Materials And Engineering, vol. 32, no. 7, pp. 569-572, 2003.

[43] N. T.-H. Pham and V.-T. Nguyen, "Behaviour of TiC particles on the Co50-based coatings by laser cladding: morphological characteristics and growth mechanism," Advances in Materials Science and Engineering, vol. 2020, Article ID 8462607, 16 pages, 2020.

[44] N. T.-H. Pham and V.-T. Nguyen, "Wear properties of TiCreinforced Co50 composite coatings from room temperature to high temperature," Advances in Materials Science and Engineering, vol. 2020, Article ID 6849081, 21 pages, 2020.

[45] C. Li and S. Chen, "Research on the properties of Ni/TiC laser cladding on 45 steel," Equipment Manufacturing Technology, vol. 08, pp. 20-22, 2011. 